\title{
SOME INTER-PARAGRAPH CONNECTIONS IN FORMAL PROSE
}

\author{
Michael P. Jordan
}

We are all aware of the practical reality of paragraphs, their psychological effects on readers, the connection between paragraph length and formality, and paragraph conventions in portraying dialogue. We, as experienced writers, have also developed sound impressionistic understandings, which collectively have been shown to form reasonable consensuses regarding paragraph boundaries in non-paragraphed texts (Koen, Becker and Young, 1969).

We are doubtless also all aware of the traditional view of the paragraph as a semantic unity of ideas with a topic sentence, development, and conclusion. The use of a topic sentence has some empirical support (Aulls, 1975; Kieras, 1978; Seltzer, 1982), and "As each proposition comes in, an attempt is made to integrate it by adding it to the appropriate already integrated set of propositions, which as a group comprises a single chunk of information." (Kieras, 1978, p. 25)

However, while it is certainly possible to find paragraphs that do follow the traditional pattern, there are many more that do not. This paper questions Kieras's claimed connection with an "already integrated" set of propositions, and the claimed "single chunk" of paragraphs. Rather than simply calling all non-standard paragraphs aberrant examples of poor writing or accusing all their writers of conspiring to contradict established norms, we should look for ourselves to establish a sound basis for teaching interparagraph connections in technical writing.

\section{TRADITIONAL VIEW}

Although some detailed work on the internal organization of paragraphs is available (e.g., Young and Becker, 1965; Becker, 1965, 1966; Kent 1984), the traditional view remains of the "standard paragraph" with a clearly stated "topic sentence", and supporting or elaborative details that "develop" the topic statement, often completed by a conclusive statement. 
We are also told that paragraphs collect related ideas into a "unity" and separate them from other unified topics in other paragraphs. And we learn about the many strategies and methods for achieving "adequate development" and "cohesion" within the paragraph.

From the traditional view, we learn little about the communicative role of the paragraph, or of larger semantic units of texts spanning several paragraphs. We learn little of the real nature of the paragraph in semiological terms, or of the semantic connection between as well as within paragraphs. And we learn little of the effects of genre, formality and audience on paragraph unity and boundary decisions. For such matters, we must turn to linguistic work in the tradition of text analysis beyond the paragraph. It is only through an examination of groups of paragraphs that we can hope to understand what paragraphs are and what they do.

\section{SOME WORK IN DISCOURSE ANALYSIS}

By now many linguists have studied the semantic connections between clauses and sentences, but few have sought to comprehend structures and patterns in whole large texts with emphasis on the role of the paragraph. Longacre (1976) identifies the paragraph as one of eight surface structures of text; he claims a status for the paragraph as being a grammatical unit between the sentence and discourse (1979), viewing paragraphs as building blocks of text structure. Grimes (1975) recognizes the complexity of the paragraph in different contexts, and identifies "spans" of information which may coincide with graphological paragraphs. Beekman and Callow (1981), and with Kopesec (1981), identify certain genre-specific "semantic paragraphs" as subsystems of meaning unity related to, but not necessarily coincident with, actual paragraph boundaries. Working within the developing theoretical framework of communication linguistics pioneered by Michael Gregory, Malcolm (1982) recognizes two sets of three strata for language structure and meaning, with "the plane of behaviour" as the discourse level at which the paragraph works.

Hoey's work (1985) is of more direct use for the practical aim here of investigating semantic connection between paragraphs. He argues

(a) that, as suggested earlier by Rodgers (1960), paragraphs must be accounted for in terms of the whole discourse of which they are a part, and not in terms of their own internal organization; 
(b) that paragraph boundaries mark significant relations or groups of relations between sentences; and

(c) that textual connecting devices at the start of paragraphs may be paragraph connectors rather than sentence connectors.

Hoey's conclusions form a useful, sound basis for further study.

\section{PARAGRAPHS IN DESCRIPTION}

Description has been defined by Jordan (1984) not only in semantic general terms, but also linguistically as the form of prose containing no relations between sentences-only items of information about the topics and sub-topics of the text. In Example 1 in the appendix, the whole communication describes the awards as topic and Ms. Carruthers and Mr. Senior as sub-topics introduced in the first sentence. The first sentence could be regarded as a topic sentence, but it is the topic of the text, and not the topic of its paragraph; this sentence provides an introduction/summary for the text, and the remainder of the text provides further details about the main topic and the two sub-topics.

The first, fifth, and sixth paragraphs provide details about the award, the first specific to the awards this year and the others providing information about the award generally. None has a topic sentence that we could reasonably regard as meeting the criteria of the traditionally defined paragraph.

Paragraph 2 provides detail about Ms. Carruthers, with supporting connection to the award and a brief side-pattern of information about $\mathrm{Her}$ studies. Paragraphs 3 and 4 do the same for Mr. Senior, the larger semantic span of information requiring two "incomplete" separate paragraphs instead of a single "complete" paragraph. Photographs and captions accompanying the text (not shown here) provide two more semiotic groups of information about the two sub-topics, answering questions concerning age, build, general appearance, manner, and racial origin. The structure of the text is shown in Figure 1. 


\section{FIGURE 1}

Structure and Paragraphing of a Descriptive Text

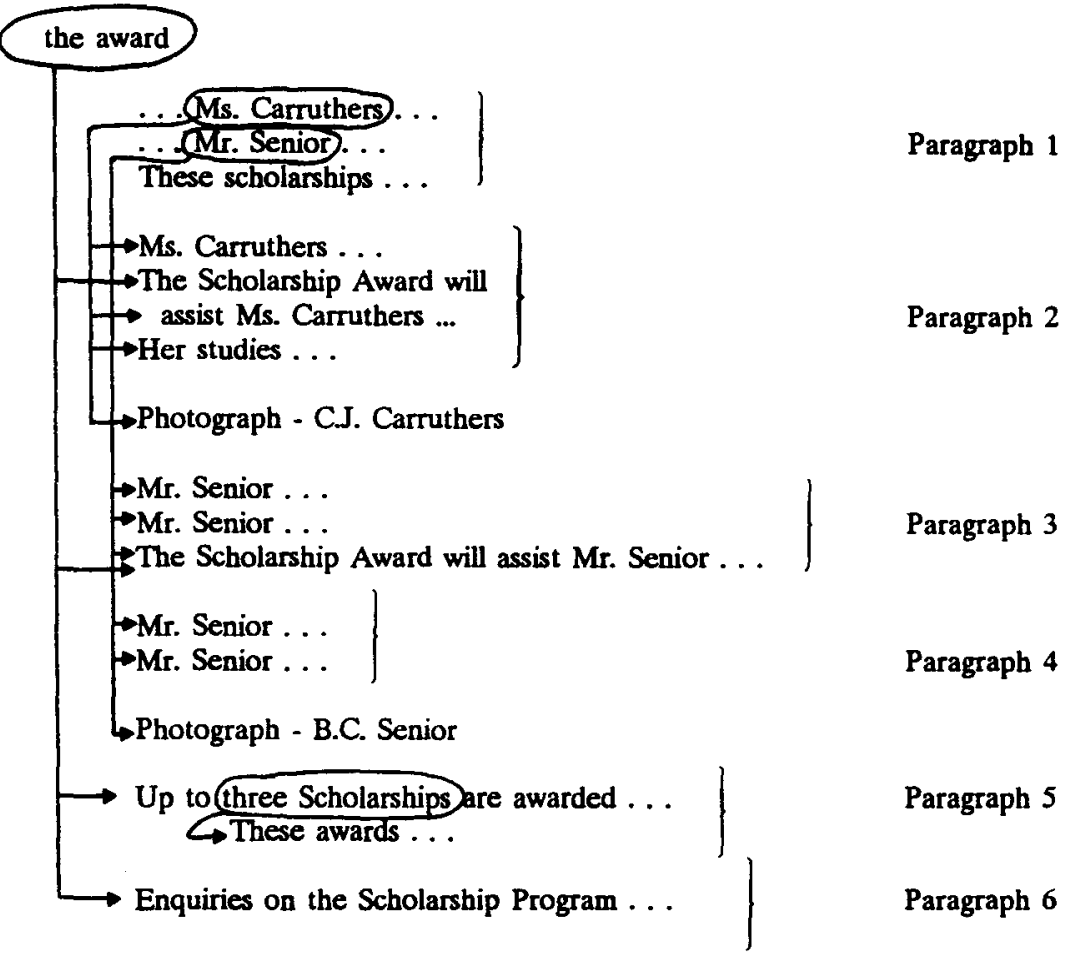

\section{ASSOCIATIONS AND PARTITIONS}

It is unhelpful to view the paragraphs of Example 1 as having topic sentences which are developed in later sentences. Instead, we should recognize that topics and sub-topics are developed; the writer is developing things in nominal groups rather than statements in clauses or a sentence. Sub-topics occur as things formally introduced as part of the detailing of the main topic (Ms. Camuthers, Mr. Senior), or as associations of a topic (Enquiries on the Scholarship Program) or sub-topic (Her studies). Such use and related description of partitives of the topic and sub-topic are illustrated in Example 2. 
Successive levels of partition of the topic are often vital for the organized arrangement of a complex subject as shown in Figure 2. Even the title of the document containing Example 2 shows four levels of partition, and the contents and headings indicate two further levels before we arrive at the span of information to be studied here. There are no "topic sentences" for any of these levels-the headings and table of contents tell readers what is being discussed. Topic sentences are possible but unnecessary:

"The stratigraphy and sedimentation of the E3D member of the Ellice formation in the Helikian Elu Basin and Hiukitak Platform of the Bathurst Inlet-Melville Sound of the Canadian Northwest Territories will now be described."

\section{FIGURE 2}

Partition of a Descriptive Topic

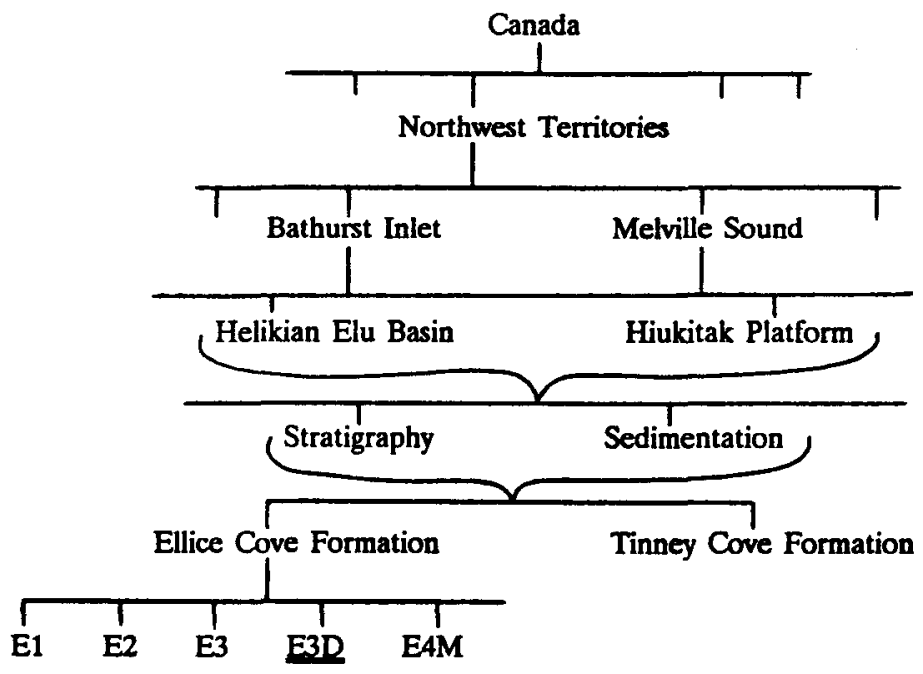


The main topic for this span is the E3D member, which is described in general terms in Paragraph 1 and more specifically in Paragraph 2. We could make statements to that effect as topic sentences of the paragraphs, but experienced writers would not insult intelligent readers by doing so. In the second paragraph, the topic is partitioned by The lower part of the member, At most locations, in the stromatolitic parts of the member, and on the Hurd Islands, with in all parts of the member marking the general applicability of the final statement.

The last three paragraphs of the span provide details of three subtopics of particular interest to the writer and readers. The sentence continuity signals (they, it, repetition, this same unit, and These (2)--and the absence of clause-relating indicators-indicate that successive sentences in the paragraph are providing further details about things in nominal groups and not developing topic sentences.

Although more-detailed work is obviously needed, it would seem that the topic sentence is a misleading, and possibly irrelevant, concept in the genre of description. In description at least, a paragraph does not develop a single "idea" or make points about a central thesis-it describes a topic or sub-topic.

\section{SPANS, DOMAINS AND PARAGRAPHS}

Every text has an overall macrostructure, which accounts for the organization and order of the major elements of the discussion. For large texts, these major elements may be books, or chapters, or sections; but for shorter texts they may simply be paragraphs or groups of sentences. The macrostructure (which may be descriptive, problem-solving, theses-backing, comparison, time-sequence, or other form) is usually signalled clearly in some orthographic form or by overt statement of the text structure.

For medium-length or large texts, we must expect to see microstructures within the major elements. These microstructures may be the same or a different genre to the macrostructure, often resulting in organized but extremely complex sequences of information-and of course microstructures may also contain mini-microstructures within them. Paragraphs play an important role in indicating the different levels of structure in a document, and these are supported by larger spans of text and their related graphological and linguistic indicators. 
In Example 3, the whole article of which this is a part forms the seventh element of a large seven-article text. The abstract places it within the larger whole, and the text we see here is an introduction to infringement and legal remedies. The introduction has three major spans:
A Paragraph 1 reminds readers of what a patent is (definition and its scope),
B Paragraphs 2-5 explain the general principles of infringement, and
C. Paragraphs 6-8 explain important exceptions to these principles.

The topic of Span B (infringement) is first explained generally in the first sentence of Paragraph 2, followed in the same paragraph by a more specific reformulation signalled by In other words. A more specific definition of infringement occurs as Paragraph 5; although this paragraph could come after Paragraph 2-or even be added to it-its marked final position in the span makes the specifics more prominent. Paragraphs 3 and 4 discuss literal and non-literal infringement respectively. By expanding Hudson's (1968) notion of "extended domain" from the sentence to the text we can view the concept of infringement as being extended over the four-paragraph span.

Similarly Span C deals with exceptions, and the domain of the first sentence of Paragraph 6 (Certain activities . . . acts) is extended to cover Paragraphs 6,7, and 8. These three paragraphs each describe an exception as an example of activities exempted as non-infringing acts. The domain of For instance extends to cover all three exemptions. By using a separate paragraph for the small amount of information on repairs, the writer has made it easier for readers to comprehend the three exemptions notedjustification for the slightly marked effect. Further marking would have been possible (though undesirable here) by introducing three exemptions and/or by numbering them, or using First, Secondly, etc.

Figure 3 illustrates the macro- and microstructures of this extract. 


\section{FIGURE 3}

An Example of Domains, Spans and Paragraphs

Every patent is granted...

Infringement is any act...

If the article... falls within

the literal language...

If the article...does not fall within the literal ambit...

Infringement occurs when...

Certain activities...are exempted...

For instance, the use or sale...

Repairs made to patented articles...

A person who...has constructed...
Paragraph 1 Span A

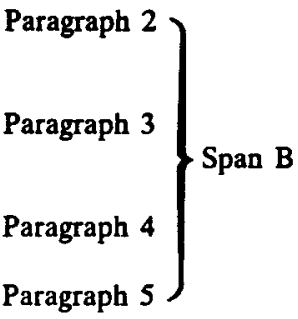

$\left.\begin{array}{l}\text { Paragraph 6 } \\ \text { Paragraph 7 } \\ \text { Paragraph 8 }\end{array}\right\}$ Span C

\section{PARAGRAPHS IN PROBLEM SOLVING TEXTS}

Work by Winter (1976), Hoey (1983), Jordan (1984b, 1988) and Flower (1981) has shown the relationship between problems and solutions in real life and the structure of the texts which describe them. For large texts the four major categories of "Situation-Problem-Solution-Evaluation" each form spans (or chapters) of information with many sub-spans or paragraphs; for mid-sized texts, we can see the problem-solution macrostructure clearly recognized as paragraphs (see Example 4), and in short texts the categories merge to create just one or two paragraphs.

In Example 4, we see five categories (Introduction/Solution-ProblemSolution-Evaluation-Implementation) as just one of a possibly infinite number of variations of the basic text scheme. Note that the domain of "problem" clearly extends throughout the second paragraph, which provides details and elements of the problem rather than "developing" the problem in the first clause or sentence. It would be possible to create a topic sentence for Paragraph 2 (e.g. "The report identifies several problems"), but that would be an unnecessarily marked form for educated readers. 
An extract from a longer problem-solution text is cited as Example 5 . The last two paragraphs are "good" and "bad" evaluations respectively, with However signalling the transition (Jordan, 1987). Here, as Hoey (1985) points out, However is a paragraph connector (not a sentence connector), signalling the change in type of information clearly indicated in the respective paragraphs. That is, the referent for However is the whole preceding paragraph--a fact we can see by using the paraphrase "In contrast with this ...", where this would refer to all the positive statements making up the previous paragraphs.

Again topic sentences are possible,

"The method has several advantages."

"However, recycled swarf also has several disadvantages."

but are not necessary and could appear a little childish. A cline of markedness for paragraph indications and connections can be recognized (from most to least marked):

(a) In contrast with all these advantages, the recycled swarf also has several disadvantages.

(b) However, the recycled swarf also has several disadvantages.

(c) In contrast with all these advantages, the recycled swarf does not have ...

(d) However, the recycled swarf does not have ...

As with all systems of marking, skilled writers use the unmarked form unless they are forced by content complexity or audience considerations to use a more marked form.

\section{DESCRIPTION/PROBLEM SOLVING TEXTS}

Many technical texts do not simply describe an invention or new system. Instead, they introduce it in terms of a solution to a problem. To do this, they start with introductory/situational material, followed by the specific problem, and then by full details of the design and its evaluation in the descriptive genre (see Figure 4). 
FIGURE 4

Typical Structure of Description and Problem-Solving

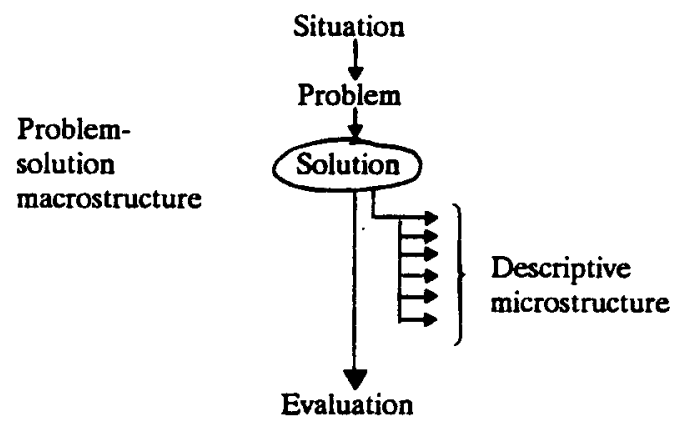

For each text the description is usually very much larger than the other elements of the macrostructure, and it is separated by sections, spans, and paragraphs in the usual way. The macrostructure is also separated by paragraphs to highlight its organization and information types. Example 6 is the start of an eight page, 38-paragraph article illustrating the principles. The first three paragraphs (together with a Conclusion later) indicate the macrostructure, and the "solution" is then described in detail in the bulk of the text. Note the clear problem-solving structure signals $A$ common problem, The solution and later Conclusion to indicate parts of the macro structure, supported by the paragraph structure.

\section{FIRST SENTENCE RELATIONS}

Outside the well-researched genres of description and problem solving, the analysis of the roles of paragraphs in the text becomes much more difficult. Some paragraphs, like those in Example 5, are homogeneous groups of information related to other homogeneous groups and we can see that a relation of meaning exists between all of one paragraph and all of another. 
FIGURE 5

An Example of a Relation Between Paragraphs

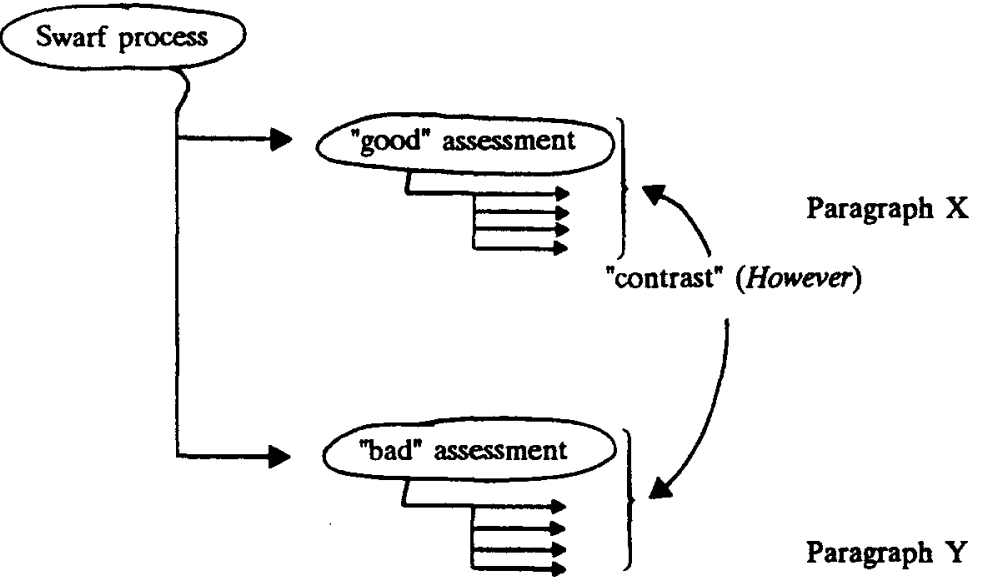

Such paragraph pairs are in line with Kieras's earlier comment on the nature of paragraph cohesion, whether or not there is a clear topic sentence. Most paragraphs, however, cannot be analyzed in this way, as they do not consist of similar types of information which "add" together to create a homogeneous group of information. Instead relations exist between the sentences of a paragraph, and we can no longer claim that the paragraphs are single units or "chunks" of information with a single simple relation between them.

In Example 7, the reduction of noise by external means is a topic introduced and discussed in the first paragraph. One means of achieving this forms the first sentence of the second paragraph, and this sentence introduces acoustic enclosures, which then form the basis of the remainder of the paragraph. In broad clause-relational terms, the two paragraphs are shown in Figure 6. 
FIGURE 6

A Clause-Relational analysis of Two Paragraphs

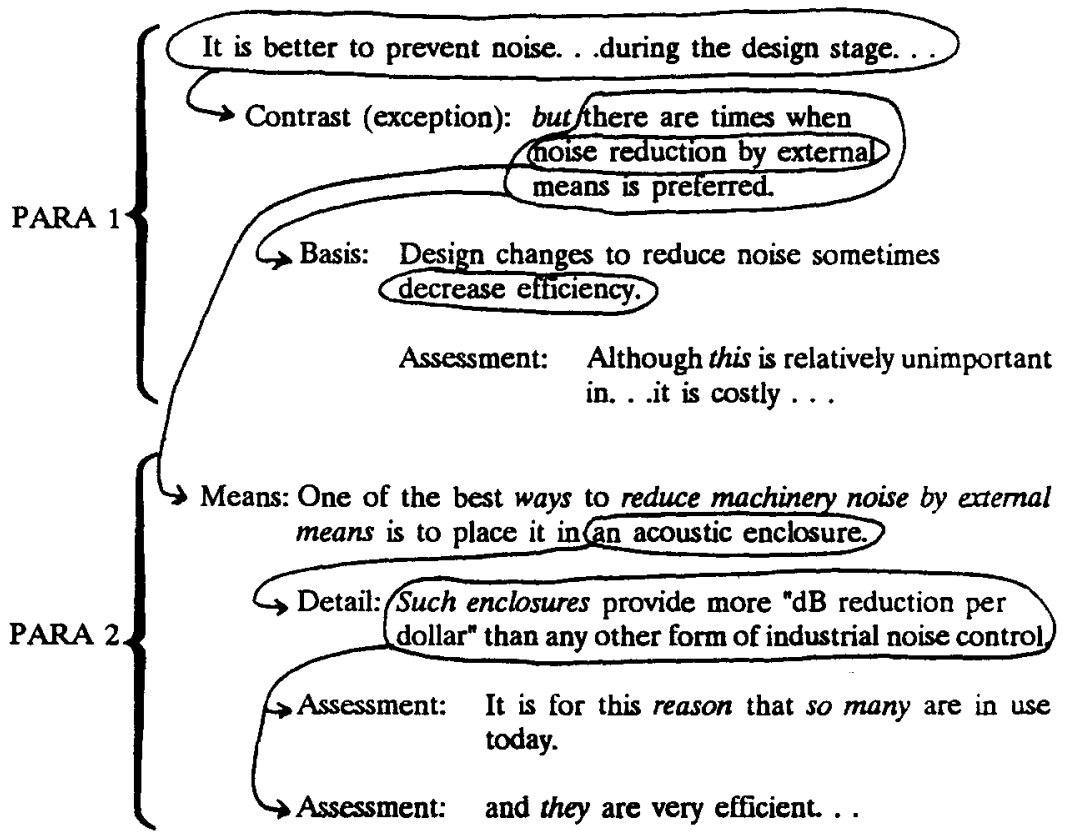

In Example 8, the referent for the cause-effect indicator consequently is the conclusion given in the preceding sentence. The domain of the lead sentence of the second paragraph extends into the next two "incomplete" paragraphs that follow to complete the total three-paragraph grouping signalled by larger leading capitals (e.g. The " $\mathrm{t} "$ as the first letter of this example).

\section{FIGURE 7}

Single-Sentence Relational Connection over a Two-Span Paragraph

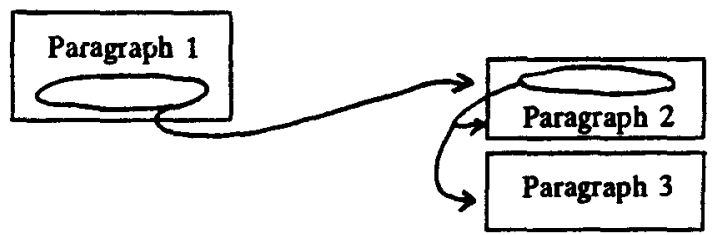


Example 9 shows a connection between four paragraphs. The subject of the lead sentence of the third paragraph is an untriggered associate of the study and its details given in the previous two paragraphs. That lead sentence provides an assessment, basis for which follows in the remainder of the third and the fourth paragraph:

FIGURE 8

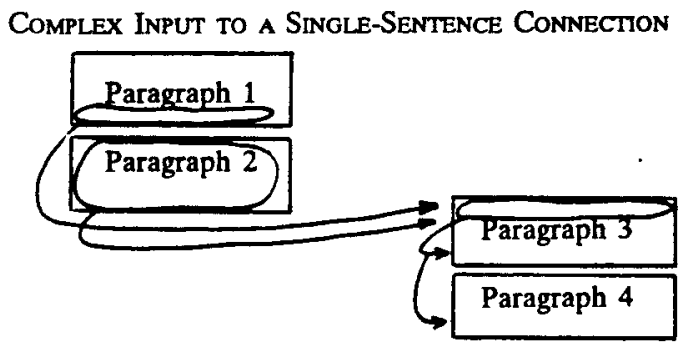

\section{INTER-PARAGRAPH REFERENTS}

Many lead sentences of paragraphs contain basic (Example 1) or associative (Example 9) connections with topics earlier in the text, and the referent (the topic being re-entered into the text) is then usually easy to discern. Other lead sentences, however, contain signals of clause relations (of Assessment, Means, Purpose, etc.) between the lead sentence and a clause, sentence, group of sentences, paragraph, or span preceding it in the text (Examples 7 and 8). When this happens, we need to be able to determine the referent, so we know what the clause relation is between. Referent identification is an essential part of the comprehension of all clause relations, but it becomes more difficult and demanding between paragraphs and spans; it is often also more important, as it is inter-paragraph connections that enable us to know what the whole text is saying.

The referent for However in Example 5 is clearly all the preceding paragraph and only that, but what is the referent for the concessive connector Despite this in Example 10? As nominal this naturally substitutes for the immediately preceding nominal or clause compatible with the new clause and the relation between the old and new clause, the referent can be seen to be the last sentence of the first paragraph. Similarly, in Example 11, the Theta procedure in the whole of the previous sentence is re-entered by This to allow the assessments in the lead sentence. And the reference for 
Consequently (=As a result of this) of Example 8 is the conclusion in the previous paragraph.

Paragraphs all have a unity of a sort in that they are bundles of information about a topic or sub-topic, and/or are significant groups of relations. But at least as importantly as their internal contents and relations, paragraphs are connected to other units of information through descriptive or relational connection. It would seem that a major role of a paragraph's lead sentence is to indicate the type of connection between previous information in the text (theme) and new information (rheme) in the lead sentence or elsewhere in the new paragraph.

\section{CONCLUSIONS}

Traditional views of the paragraph-and most prescriptive teaching of the subject-not only are silent on the important issue of how paragraphs are connected together, but also fail to recognize the effects of genre on paragraph roles and connections. Also the traditional topic sentence is likely to be a marked form, and insistence on its use could cause students to use techniques which experienced writers would avoid. Finally there is little recognition that the "topic" or binding quality of a paragraph could be a noun or noun phrase, or a clause, or an unstated general concept epitomizing the thrust of the paragraph.

While we still have little to replace the traditional view, we can at least recognize the effects of descriptive and problem-solving genres on paragraph unity and text cohesion. We can also recognize that there can be relations between paragraphs, or relations between parts of paragraphs, as well as within them. We can also understand more fully a major role of many paragraph lead sentences in showing the type of textual connection and what parts are being connected; and we can view the topic sentence as commonly a marked form of expression. By using established ciauserelational techniques, we can also analyze all the relations in a complex text, and perhaps then see how they should best be "bundled" into paragraphs.

Paragraph boundaries more than other textual elements are often dependent on formality and personal preference, and students need to develop a sensitivity towards the effects paragraphs-and especially lead sentences-have on comprehension and tone. While it is quite easy for us to teach and insist on use of the standard paragraph as having "singleness of purpose, based on a topic sentence that states the core idea of the paragraph" and that holds "to one point of view, one attitude and one tense" 
(Brusaw, Alred, and Oliu, 1976), we must ask whether such constraining concepts really help students to achieve a true impressionistic awareness of language.

\section{APPENDIX}

\section{Example 1}

\section{DET NORSKE VERITAS/THE CANADIAN INSTITUTE OF MARINE ENGINEERING SCHOLARSHIPS AWARDED}

The Classification Society Det norske Veritas (Canada) Lid., and The Canadian Institute of Marine Engineering were pleased to announce recently the award of Scholarships for 1985 to Ms. Constance Jean Carruthers of St. John's, Newfoundland and to Mr. Barry C. Senior of Lewin's Cove, Placentia Bay, Newfoundland. These Scholarships are for tuition fees to a maximum of $\$ 1000$ (Can) each.

Ms. Carruthers is a graduate of Memorial University of Newfoundland in Shipbuilding Engineering (Naval Architecture). The Scholarship Award will assist Ms. Carruthers in pursuing graduate studies in Naval Architecture at the Technical University of Nova Scotia, Halifax. Her studies will include subjects such as dynamics of ships and offshore structures, coastal engineering, ship structure analysis, ship power and propulsion.

Mr. Senior is a graduate of a three year program in Mechanical Engineering Technology at the Institute of Fisheries and Marine Technology, St. John's, Newfoundland, and was granted a Diploma of Technology. Moreover, Mr. Senior received the Governor General's Bronze Medal for being first overall in his Program. The Scholarship Award will assist Mr. Senior in pursuing a Bachelor of Engineering Degree (Co-Operative Program) at the Memorial University of Newfoundland, starting in the fall of 1985.

Mr. Senior now possesses a Transport Canada 4th Combined Certificate of Competency with exemption credits for parts of 3rd Class, 2nd Class, and 1st Class Tickets. In conjunction with the Co-Operative Program, Mr. Senior plans to obtain his 1st Class Ticket and pursue a career as a Fleet Engineer, a Marine Surveyor or as a Research and Development Engineer.

Up to three Scholarships are awarded annually to deserving suitably qualified Canadian students pursuing undergraduate or post-graduate education in Naval Architecture or Marine Engineering. These Awards were created by Det norske Veritas and are administered by Det norske Veritas and The Canadian Institute of Marine Engineering.

Enquiries on the Scholarship Program, as well as submission of Applications, which should be typewritten, should be directed to:

Det norske Veritas/The Canadian Institute of Marine Engineering Scholarships in Naval Architecture and Marine Engineering c/o The Executive Director, The Canadian Institute of Marine Engineering Suite 706, 116 Albert Street Ottawn, Ontario K1P 5G3

Marine Engineering Digest, July 1985, p. 8. 


\section{Example 2}

\section{E $_{3 D}$ MEMBER}

This member is transitional into and overlies the $\mathrm{E}_{3}$ member, although the boundary is difficult to place precisely, due to the nature of the two units. The $E_{3 D}$ member consists of interbedded doloarenite, quartzite, quartzose doloarenite, dolomitic quartzite, stromatolitic dolomite, siltstone, and oolitic dolomite.

The lower part of the member consists predominantly of quartaite and dolomitic quartzite, with dolomite increasing upwards at the expense of quartzite. The quartzite is thin- to medium-bedded, planar crossbedded and commonly rippled. At most locations it is interbedded on a large and small scale with the doloarenite. Thin laminae of shale and mudstone also occur in the stromatolitic parts of the member. Sand cracks, mud cracks, and shale flake and chip conglomerate are common in parts of this member and colites are present on the Hurd Islands (Fig. 2). Stromatolitic, fine-grained doloarenite occurs in all parts of the member.

The stromatolites occur as continuous undulose sheets with low relief $(3-10 \mathrm{~cm})$ up to $1.5 \mathrm{~m}$ thick, and show no preferred elongation direction. Commonly they stan directly on dolomitic quartzite and are overlain by tabular bioclastbearing quartzose doloarenite.

A section composed predominantly of coarse grained quartzite west of Warrender Bay (Fig. 2) appears to lie within the member. It consists of mega-planar crossbeds (sand waves?) and also small scale troughs. The crossbeds and sand waves(?) show distribution patterns consistent with paleocurrents in the remainder of the member. This same unit may outcrop on the eastern end of the Hurd Islands, where massive, laminated coarse grained quarzite is intimately associated with the dolomitic part of the member. These may represent primary, through-delta distributary channels which fed sediments to the more distal parts of the shelf and basin.

Some of the laminated fine grained doloarenite beds in the western part of the area have laminations composed of singie grains of quartz. These are interpreted to have been wind-blown, as there is no other apparent means of transporting and depositing a singlegrain lamination of quartz in a dolomite.

Stratigraphy and Sedimentation in the Helikian Elu Basin and Hiukitak Platform, Bathurst Inlet-Melville Sound, Northwest Territories, FHA Campbell, Geological Survey of Canada, Paper 79-8, p. 9.

Reproduced with permission of the Minister of Supply and Services Canada. 


\section{Exmple 3}

\section{AN ENGINEER'S GUIDE TO THE CANADIAN PATENT SYSTEM-PART 7 BY S. BURSHTEIN}

In previous articles we have discussed how to obtain a patent and commercially deal with one. A patent is only as veluable $a$ the ability of the patentec to enforce it against infringers. In this part of the series, patent infringement $a$ well 2 legal setions are explained.

EVERY patent is granted to a patentee for a term of seventeen years from its date of grant. A patent grants to a patentee the right to exclude others from making, using or selling the invention covered by it. The right is, however, subject to the other provisions of the Patent Act. The mere fact that one has gone through the often rigorous process of obtaining a patent does not necessarily mean it is valid and enforceable, although a patent is presumed valid.

Infringement is any act done during the life of the patent without the consent of the patentee that interferes with the exclusive right granted by the patent. In other words, patent infringement is the unauthorized marking, using or selling of the patented invention within Canada during the term of the patent.

If the article or process being made, used or sold by the alleged infringer falls within the literal language of one or more of the claims of the patent, there is what is termed textual or literal infringement. The infringing article or process is to be compared to each claim and not to the patentee's product. Therefore, the drafting of claims of sufficient breadth to cover possible variations is extremely important.

If the article or process does not clearly fall within the literal ambit of the claims, a court may still find there to be infringement if the substance of the patentee's invention is appropriated. Protection against infringement would be futile if it afforded no relief where a defendant made minor mechanical or structural variations in his device and yet had broadly taken the substance of the invention protected. On the other hand, the defendant will escape infringement by showing that what he has done does not fall within the essence or principle of the patented invention.

Infringement occurs where one makes in Canada a patented article whether for private use or public sale; sells in Canada a patented article; imports into Canada a patented article; imports into Canada an article made by an apparatus patented in Canada; imports into Canada an article made by a process patented in Canada; uses in Canada a patented article or process; or knowingly, for one's own benefit, induces another to infringe a patent.

Certain activities which ordinarily fall within the scope of the monopoly granted to the patentee are exempted as non-infringing acts. For instance, the use or sale of a patented invention having its source in the patentee or a licensee does not infringe a patent. Where such a patented article is sold without restriction in the terms of sale, the purchaser acquires an absolute title and is at liberty to resell it or deal with it as he pleases. However, any dealing with the patented invention beyond that which is included in the permission accorded by the license is an infringement. 
Repairs made to patented articles in good faith do not constitute infringement. However, a reconstruction of the article is a re-making and is not exempted.

A person who, before the issue of a patent, has purchased, wnstrucied or acquired any invention for which a patent is afterwards obtained, is permitted to use and sell to others any specific article purchased, constructed or acquired before the issue of the patent therefor without liability to the patentee so that one may liquidate inventory acquired before the patent is granted. Where a patent includes claims for an apparatus in regard to which a defendant is entitled to the benefit of this immunity, the immunity extends to the use of the apparatus under any process claimed in the patent. It is not certain whether this immunity extends to a process independent of an apparatus.

Engineering Digest, November 1984, p. 22.

Reproduced with permission of Engineering Digest.

\section{Erample 4}

\section{UNIVERSITY OF THE SHOP-FLOOR}

"Selected well-managed and successful manufacturing firms should, in partnership with university and polytechnic departments, become "teaching companies", says a report published jointly by the Science Research Council and the Department of Industry last week. The report proposes the "teaching company"-analogous to a teaching hospital-as a means "to improve postgraduate training in manufacturing engineering and to advance our knowledge of successful production and management methods and how to apply them in industry."

The problem, as defined by the working group that produced the report, is that British engineering industry has, in recent years, performed badly in comparison to its major competitors, and that the blame for this cannot be placed solely on low investment. University entry to engineering has been declining, while the pay and status of engineers in British society is low. The under-utilisation and undervaluation of highly qualified engineers in British manufacturing industry and the relative aversion of schoolchildren and undergraduates to manufacturing engineering feed on each other", says the report.

To overcome these difficulties, the working party proposes a scheme, which would be financed partly by SRC, to train would-be production engineers "in live industrial conditions in firms whose management are receptive to innovation in manufacturing techniques". The training would be backed up by appropriate course work.

As a foreword to the report makes clear, the idea is not new, but a variant of one proposed by Dr. D.T.N. Williamson of Xerox Research Ltd, in 1973 to provide "the engineering equivalent of a teaching hospital, where experienced practitioners, researchers and students intermingle and cross-fertilise ideas whilst doing a job in the real environment".

Neither SRC nor DI will commit itself to the scheme at the moment-as with other, similar SRC reports, they bave called for comments from interested bodies. These should be sent to the Joint Secretaries of the Working Party on the Teaching Company Scheme, 
at SRC, PO Box 18, Swindon SN1 5BW or the Research Requirements Division, Dept of Industry, Abell House, John Islip St, London SW1P 4LN by 31 March, 1976.

New Scientist, January 1, 1976, p. 30.

Reproduced with permission of New Scientist.

\section{Enmple 5}

The tensile and impact properties of the extruded rod listed in Table 2 with values for conventional 6061 aluminum alloy show the extruded material is even stronger than the conventionally produced aluminum alloy and has seven times the impact strength. Chemical analysis of the swarf sheet gave compositions within the limit for a 6061 alloy.

One of the original researchers, Dr. H.M. Skelly, believes that material with properties at least equal to and very possibly superior to conventional material can be produced by processing swarf without remelting. The process, in addition to conserving metal, is more energy efficient and produces less pollution than the present practice of remelting. It also eliminates the necessity of replacing alloying elements lost during remelting.

However, the recycled swarf does not have the same properties as the parent metal and could not supply the same market. To be economically feasible, new markets would have to be developed. Also, because of the cost of rolling and extrusion equipment, and because industries that produce swarf do not have that equipment, it is necessary to devise ways of processing the swarf with the existing facilities.

GEOS, Fall 1980, p. 17.

\section{Example 6}

Optimizing the design of a computer room environmental control system is, by definition, a demanding task. Stable temperature and humidity conditions are a must, but reliability and energy efficiency also enter as major factors. The criteria may require that computer operations be able to proceed 24 hours a day, 365 days per year with no scheduled downtime except under the most extraordinary circumstances. Still, redundancy must be kept to a minimum for the sake of economy. This article results from the design, construction and operation of a computer/administration facility for American Telephone and Telegraph located near Atlanta, Georgia. The data given here were measured at this computer facility. The facility is comprised of 130,000 sq $\mathrm{ft}$ of raised floor, $230,000 \mathrm{sq} \mathrm{ft}$ of administrative space and $30,000 \mathrm{sq} f \mathrm{f}$ in the central plant. The design criteria called for the ability to maintain $72 F \pm 2 F(22 \mathrm{C}), 50$ percent relative humidity \pm 5 percent in all computer areas for an average equipment heat release of $45 \mathrm{~W} / \mathrm{sq} \mathrm{ft}$.

\section{Dempoint control system}

A common problem occurs in computer rooms when floor-mounted air handling units, each with its own reheat and moisture addition system for humidity control, begin to "fight" each other. One unit can be seen delivering full humidification while the unit next to it is cooling for dehumidification and reheating to maintain room temperature. This 
condition is caused by the combination of the narrowband controls provided with these units being slightly out of calibration and local room conditions providing slightly different return air conditions to adjacent units.

The solution provided herein is commonly referred to as a dewpoint control system. Basic to its concept is the provision of central humidification and dehumidification functions, along with the provision of multiple foor-mounted cooling units in a sensible cooling mode only. A schematic diagram of this system is shown in Figure 1 .

The unique feature of this system is that it does not attempt to control room relative humidity directly. Instead, it controls the dewpoint of the air circulating in the computer room.

ASHRAE Joumal, April 1988, p. $20-21$.

Reproduced with permission of ASHRAE Journal.

\section{Example?}

It is better to prevent noise generation in machinery during the design stage than to try to reduce it later, but there are times when noise reduction by external means is preferred. Design changes to reduce noise sometimes decrease efficiency. Although this is relatively unimportant in small, fractional horsepower equipment, it becomes costly and wasteful in large, high-horsepower machinery that has been designed to obtain maximum performance and efficiency.

One of the best ways to reduce machinery noise by external means is to place it in an acoustic enclosure. Such enclosures provide more "dB reduction per dollar" than any other form of industrial noise control. It is for this reason that so many are in use today, and they are very efficient when designed and installed correctly.

Compressed Air, January 1983, p. 12.

Reproduced with permission of Compressed Air.

\section{Example 8}

Then Richard H. Dalitz, working at Cornell University, demonstrated that properties of the decay of a particle called the $K$ meson through the weak interaction appeared to be inconsistent with the notion that nature does in fact differentiate between left- and righthandedness. In the course of efforts to understand this, Tsung Dao Lee and Chen-Ning Yang proved in 1956 that there is nothing contradictory about supposing the weak interactions define a screw direction. In essence, Lee and Yang's theory, for which they were awarded a Nobel prize in 1957, shows that the $P$ mirror could be asymmetric with respect to the weak interactions. In December, 1956, Chien Shiung Wu of Columbia University, Ernest Ambler of the National Bureau of Standards and other collaborators did an experiment suggested by Lee and Yang. The experiment showed conclusively that the weak interactions do define a screw direction: nature discriminates between left- and righthandedness. 
Consequently Alice can tell whether she is in the looking-glass world or in her home world by doing an experiment along the lines of Wu and Ambler's. She places a cylinder of cobalt 60 , an isotope of cobalt that decays by emitting electrons through the weak interactions, in a magnetic field generated by electrons flowing counterclockwise around a circular wire loop [see left half of illustration below]. Following elementary laws of physics, the magnetic field generated by the electrons moving in the loop points downward. Now, the nuclei of all atoms have a certain spin, or angular momentum, that causes them to act like tiny bar magnets spinning about their axes. In the case of cobalt nuclei the magnetic field aligns the nuclear spins downward, in the direction of the field.

Alice, in her home laboratory, finds that the electrons emitted by cobalt through the weak decays travel upward, in the direction opposite to the auclear spins. Alicethrough-the-looking-glass [see right half of illustration below] performs the same experiment, but because the electrons in the wire loop in the looking-glass world move clockwise, they generate a magnetic field that points upward and aligns the spins of the cobalt nuclei upward. The electrons emitted by the cobalt nuclei in the looking glass therefore travel downward. That means the real world and the looking-glass world are not absolute reflections of each other. The symmetry of the $P$ mirror is broken.

Scientific American, February 1988, p. 50-51.

From 'A Flaw in a Universal Mirror,' by Robert K. Adair. Copyright $\bullet 1988$ by Scientific American, Inc. All rights resenved.

\section{Example 9}

An interesting analysis of power supply reliability that was reported in POWER ENGINEERING last May (page 5) deserves a quick summary here. A study done by a consulting firm called Applied Economic Research, sponsored by the Utility Data Institute, used a probabilistic approach to calculating the adequacy of power supplies in the 1990 s.

The study used the construction schedule reported by NERC, a range of peak load growth rates with assigned probabilities, and the average "unavailability" of U.S. generating capacity at the time of the summer peak, based on unpublished NERC data.

The outcome was sobering. The study concluded there is a $10 \%$ chance that the generating reserve margin will be insufficient to cover the summer peak in 1992 . There is a $50 \%$ chance the shortfall will occur by 1997 , says AER.

Factoring in the effect of aging capacity on the unavailability rate would probably move those dates up. "..the U.S., more likely than not, will experience electricity supply shortages by the end of the century," the study warns.

Power Engineering, April 1988, p. 24-25.

\section{D.mple 10}

US Government funding for Earth Observation Satellite (Eosat) has been reduced. The company, which took over the Government-subsidised commercialisation of Landsat remote- 
sensing images in 1984, is still struggling against Congressional scepticism, reports Tim Furnise This reduction may hit future satellite plans.

Despite this, the company still hopes to launch a new satellite, Landsat 6, in 1991. It also hopes that Landsat 5 will keep operating beyond its design life until its successor is launched, to prevent a "data gap". Landsat 4, although still operating and returning some images, lost its thematic mapper due to a power failure.

Flight International, March 5, 1988, p. 34.

\section{Emmple 11}

For example, the conventional procedure is for a concept to be styled for appearance and then turned over to engineers who design the innards and develop technical details. Finally, the engineers turn it over to manufacturing people who design tooling and provide price quotations. Theta, in contrast, does all of this simultaneously across a broad front, with stylists, technical development teams, and fabricators each working on their own piece of the problem at the same time.

This obviously requires some radical rethinking of the engineering process, with some tenets running directly against conventional wisdom. For example,

Machine Design, April 21, 1988, p. 25.

\section{REFERENCES}

1. Aulls, M. "Expository Paragraph Properties that Influence Recall," Journal of Reading Behavior, 7, 1975, 391-400.

2. Becker, A.L. "A Tagmemic Approach to Paragraph Analysis," College Composition and Communication, 16(4), 1965, 237-242.

3. Becker, A.L. "Symposium on the Paragraph," College Composition and Communication, 17(2), 1966, 67-72.

4. Beekman, J. and Callow, J. Translating the Word of God, Zondervan, 1974.

5. Beekman, J., Callow, J. and Kopesec M. The Semantic Structure of Written Communication, Summer Institute of Linguistics, Dallas, Texas, 1981.

6. Brusaw, C.T., Aldred, G.J. and Oliu, W.E. Handbook of Technical Writing, St. Martins, 1976. 
7. Flower, L Problem-Solving Strategies for Writing, Harcourt, Brace, Jovanovich, 1981.

8. Grimes, J. The Thread of Discourse, Mouton, 1975.

9. Hoey, MP. On the Surface of Discourse, Allen and Unwin, 1983.

10. Hoey, M.P. "The Paragraph Boundary as a Marker of Relations between the Parts of a Discourse," MALS Joumal, New Series, 10, 1985, 96-107.

11. Hudson, R.A. in Sentence and Clause in Scientific English, Huddleston, R.D., Hudson, R.A., Winter, E.O. and Hennici, A., University of London, OSTI Project, 1968.

12. Jordan, M.P. Fundamentals of Technical Description, Krieger, 1984a.

13. Jordan, M.P. Rhetoric of Everyday English Texts, Allen and Unwin, $1984 b$.

14. Jordan, M.P. "The Language of Evaluation," Technostyle, 6(2), 1987.

15. Jordan, M.P. "How Can Problem-Solution Structures Help Writers Plan and Write Documents," in Solving Problems in Technical Writing, L. Beene and P. White, eds., Oxford, 1988.

16. Kent, T.L "Paragraph Production and the Given-New Contract," Joumal of Business Communication, 21(4), 1984, 45-66.

17. Kieras, D.E. "Good and Bad Paragraph Structure in Simple Paragraphs," Joumal of Verbal Leaming and Verbal Behavior, 17, 1978, 13-28.

18. Koen, F, Becker, A.L. and Young, R. "The Psychological Reality of the Paragraph," Joumal of Verbal Learning and Verbal Behavior, 8, 1969, 49-53.

19. Longacre, R.E. An Anatomy of Speech Notions, Peter de Ridder, 1976.

20. Longacre, R.E. "The Paragraph as a Grammatical Unit," in Syntax and Semantics (Givon, T., ed.), Academic Press, 12, 1979. 
21. Malcolm, K. "The Paragraph: What is it? Some Traditional and Contemporary Proposals," The Ninth LACUS Forum, J. Morreall, ed., 1982, 382-389.

22. Rodgers, P.C. "A Discourse Centred Rhetoric of the Paragraph," College Composition and Communication, 17(1), 1966, 2-11.

23. Seltzer, J. "Certain Cohesion Elements and the Readability of Technical Paragraphs," Joumal of Technical Writing and Communication, 12, 1982, 285-300.

24. Young, R. and Becker, A.L. 'Toward a Modern Theory of Rhetoric: A Tagmemic Contribution," Harvard Educational Review, 35, 450-468.

25. Winter, E.O. "Fundamentals of Information Structure," The Hatfield Polytechnic, 1976 mimeo.

Michael P. Jondan teaches technical writing and linguistics at Queen's University. 